\title{
Enhanced Material-Driven Design Methodology: Luffa Cylindrica's Case
}

\author{
Alejandro Plumed ${ }^{1}$, David Ranz ${ }^{1(凶)}$, Ramón Miralbes ${ }^{1}$, and Gustavo Vargas ${ }^{2}$ \\ ${ }^{1}$ Departamento de Ingeniería de Diseño y Fabricación, EINA, Universidad de Zaragoza, \\ C/ María de Luna s/n, 50018 Zaragoza, Spain \\ dranz@unizar.es \\ 2 David L. Hirschfeld, Department of Engineering, Angelo State University, \\ San Angelo, TX, USA
}

\begin{abstract}
As society and regulations demand more ecological materials, we must focus on finding new properties in potential candidates that make them really feasible and open up new possibilities. A new methodology is established to reach that goal, based on already existing ones, but with a broader vision; more focused on the use, and not solely on the product. To put it into practice, it's been applied on Luffa Cylindrica, a plant with interesting properties. A volumetric, mechanical and perceptual characterization of it has been carried out, so that we can create new concepts specially linked to that. One of these paths has been fully developed to the point of getting a physical prototype, while more complex ones have been suggested. The stated methodology may be used as a flexible guide to find new materials not only more environmentally-friendly, but better than what's stablished.
\end{abstract}

Keywords: Natural $\cdot$ Material $\cdot$ Eco-friendly $\cdot$ Luffa $\cdot$ Design methodology

\section{Introduction}

Social pressure leads to the use of more ecological solutions in the industry. The problem is that they don't usually match the features of their traditional counterparts, and end up succeeding by mandatory regulation. Materials choice is one of the fields in which this behavior applies.

The most effective approach to this problem is to find applications in which each new material excels, instead of trying to substitute established solutions with worse alternatives that will not naturally spread in the market.

There are some methodologies that already focus on the material itself to discover its maximum potential. Material Driven Design (MDD) [1] is one of those, in this case specifically thought for eco-friendly materials. Material Experience Lab created the MDD Methodology [1], in order to give a clear guide to accomplish innovative products using that kind of eco-solutions. This methodology is highly focused on the experiential characteristics of the materials, leading to final outcomes that accurately reflect the core values of them. A new methodology is established to reach that goal, 
based on already existing ones, but with a broader vision; more focused on the use, and not solely on the product. Here, a modified version of it is stated, with a broader focus, not only suitable for consumer-oriented products, but for large-scale applications. This enhanced new approach methodology has been applied on Luffa Cylindrica, the dried fruit of a plant with interesting properties. A volumetric, mechanical and experential characterization of it has been carried out, so that we can create new concepts specially linked to those properties. One of the processes associated to this methodology was fully developed till a physical prototype was manufactured, while more complex ones have been suggested. The stated methodology may be used as a flexible guide to find new eco-friendly materials applications, which outperform their predecessors.

\section{Methodology}

This new methodology based on the MDD is stated (Table 1). While MDD is more product-guided, its modified version covers more application fields, so it can deliver higher-level industrial uses, while not dismissing the outcomes of the MDD.

Table 1. Comparison between methodologies.

\begin{tabular}{l|l|l}
\hline Stage & MDD & Modified MDD \\
\hline Phase I & - Mechanical characterization & - Volumetric characterization \\
& - Manufacturing processes & - Mechanical characterization \\
& - Mechanical information & - Manufacturing processes \\
& - Full experiential characterization & - Mechanical testing \\
& - Broad research & - Material benchmarking \\
& - Properties & - Light experiential characterization \\
& - Cost & - Broad research \\
& - Properties \\
\hline Phase II & "Manifesting materials experience & - Cost \\
\hline Phase III & patterns" & - Use cases \\
& patterns" Applications/Concepts \\
\hline Phase IV & - Concepts & - Development of the product or \\
& - Development & application \\
\hline
\end{tabular}

This new approach puts more emphasis on mechanical and volumetric analysis of the material, so that a more specific characterization of it can be reached, and delays the use of user-centered techniques of the MDD to later stages, when the application path is defined and the specific tools to be used are clear. 


\section{Phase I: Luffa Cylindrica Understanding}

Luffa Cylindrica is a Cucurbitaceae plant [2] growth in warm weather. However, the Luffa, commonly referred to as vegetable sponge or luffa cloth, is obtained from its matured dried fruit. Although it's already used for personal care as scrub, and eaten in eastern countries like India, China or Vietnam, no industrial application of it has been found yet.

\subsection{Volumetric Characterization}

The first step was to get a simple model of the Luffa in a CAD file, in order to know its internal structure and potentially get a micromechanical model [3]. Due to its fibrous structure, a medical-oriented program called 3DSlicer was used. It can generate volumes with cross sections as inputs, which was a good approach in this case, as substantial variability can be observed within a few centimeters (Fig. 1).
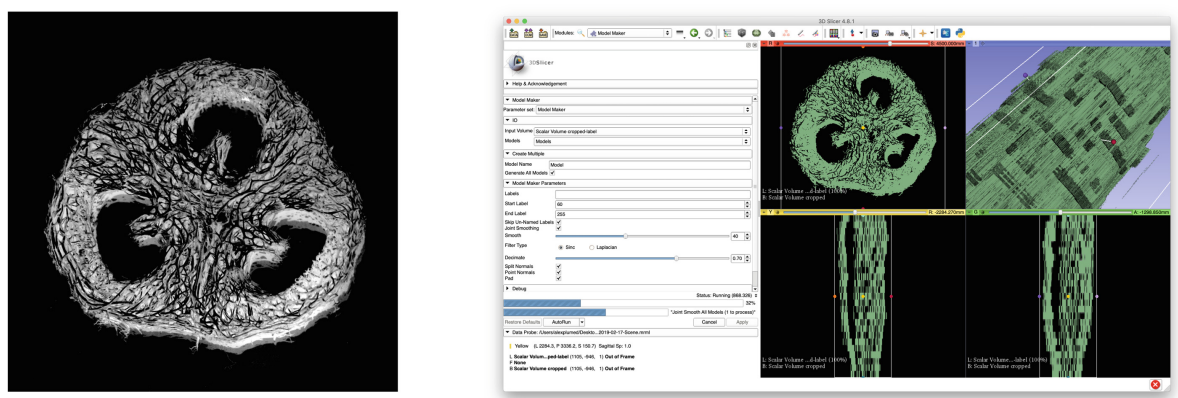

Fig. 1. Luffa slice and smoothing process in 3DSlicer.

Due to the superficial smoothness of the Luffa, the minimum thickness that could be achieved for each slice was $10 \mathrm{~mm}$ and thus one piece was divided in 25 parts. In that way several full models of Luffa were modelled and analysed.

While conducting a full CT scan would be useful in order to get an exact micromechanical model, stacked up 2D images, along with the smoothing tools provided by 3DSlicer is an economic pathway to create an accurate CAD file.

\subsection{Mechanical Characterization}

Mechanical tests were carried out, both on the material on its own and together with linen as a composite sandwich configuration. The last case is particularly interesting. Bending tests were executed for Luffa-Linen, Cork-Linen and EPS-Linen, according to ASTM C393/C393M [4]. While Cork's showed better values in each measured mechanical property, Luffa's outperformed EPS' in core shear ultimate strength (a mean of 0,261 MPa and $0,198 \mathrm{MPa}$ respectively) and facing ultimate strength (a mean of 12,61 MPa and $10,4 \mathrm{MPa}$, respectively), with the first one being substantially less dense. 
Additionally, testing the Luffa on its own, it was possible to place it in a material benchmarking graph (Fig. 2). Specifically, "Compact Luffa Cores", meaning that the side surface of the material (the least dense part) was removed, while the core material of 4 slices was compacted, so that they made up a less empty block.

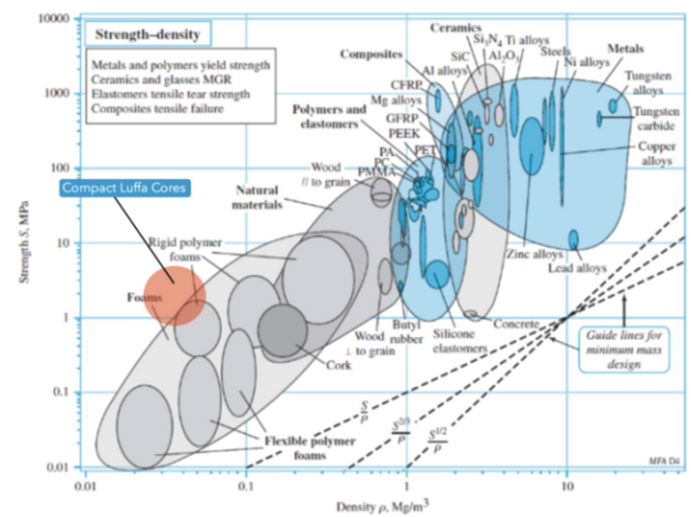

Fig. 2. Compact Luffa Cores in material Ashby' chart.

\subsection{Other Properties}

Aside from mechanical properties, Luffa also shows interesting capabilities that could drive the final use of the material. Among them, acoustic characteristics (up to $87 \%$ absorption rate as a composite [5]), magnificent permeability and oil dissipation [8], up to $220 \%$ higher deflective compression index than traditional alternatives [6] or the possibility to use it as a biocompatible filler together with PLLA, cellulose and HA [7].

As stated before, a light experiential characterization was also carried out with 24 people, concluding that Luffa is seen as a more expensive, heavier and harder material before touching it.

\section{Phase II: Conceptualization}

Once the material was characterized, it was time to associate its properties to random isolated uses, and later evaluate the potential and feasibility of each option to follow one path.

The two most interesting alternatives were: a product based on its oleophilic characteristics to help with oil spills and a saddle that made use of its open-structure and hydrophobic properties.

Although the first concept also seems quite attractive in order to take advantage of material properties. It raised serious doubts about whether, as a single-and-critical purpose product, it could be fully developed and tested in the limited given budget and timespan. Finally, the second option was chosen and fully developed till prototype manufacturing. 


\section{Phase III and IV: Development and Prototyping}

The saddle was developed as a sandwich composite using $100 \%$ ecological materials, such as a luffa core and linen reinforced faces. This provides an equivalent structural behaviour than traditional one. Besides, the plant sponge features open-core structure, which provide an effective airflow to dissipate the sweat.

Its molds were 3D printed. Inside them, the material was placed and impregnated with eco-epoxy resin, achieving an almost 100\% ecological solution (Figs. 3 and 4).
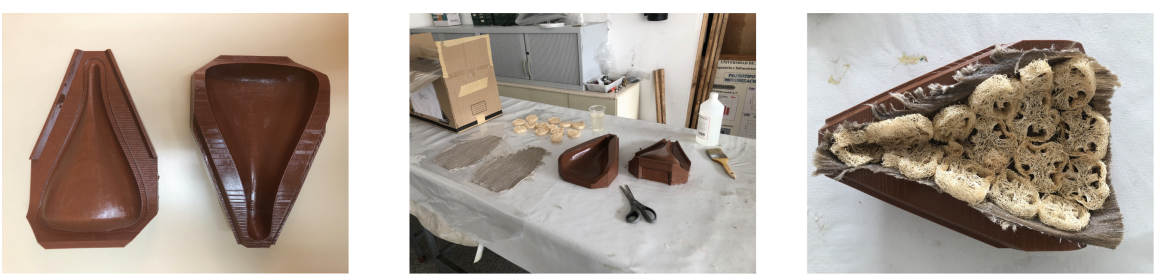

Fig. 3. Prototyping process.
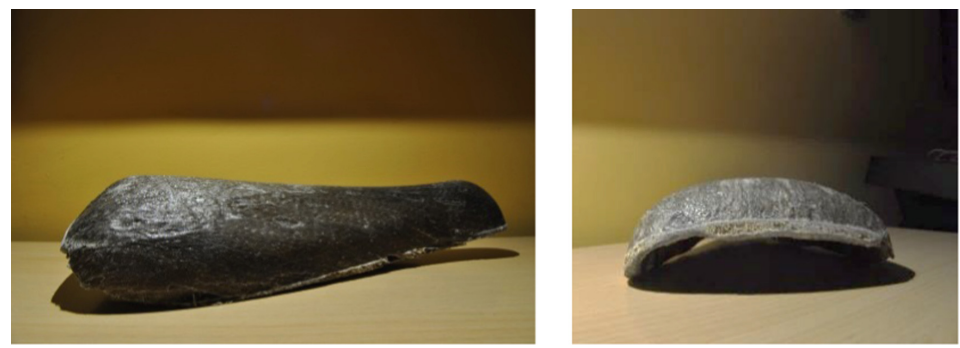

Fig. 4. Final prototype.

\section{Conclusions}

With the Luffa, it's been checked how the modified version of the MDD can deliver both final products and high-level industrial applications. This methodology may serve as a flexible guide to work with eco-friendly materials, find a suitable application and fully characterize them in many points of view.

Acknowledgments. The authors thank Iberluffa (Iberica de esponjas vegetales) for providing material needed for this research work. 


\section{References}

1. Karana, E., Barati, B., Rognoli, V., Zeeuw van Der Laan, A.: Material driven design (MDD): a method to design for material experiences. Int. J. Des. 9(2) (2015). https://www.ijdesign.org/ index.php/IJDesign/article/view/1965/693. ISSN 1994-036X. Accessed 21 Jan 2020

2. Luffa.info. https://luffa.info/luffagrowing.htm. Accessed 20 Jan 2020

3. ASTM C393 / C393M - 16. Standard Test Method for Core Shear Properties of Sandwich Constructions by Beam Flexure

4. Islam, M.R., Tudryn, G., Bucinell, R., Schadler, L., Picu, R.C.: Morphology and mechanics of fungal mycelium. Sci. Rep. (2017). https://doi.org/10.1038/s41598-017-13295-2

5. Körük, H., Genc, G.: Investigation of the acoustic properties of bio luffa fiber and composite materials. Mater. Lett. 157, 166-168 (2015). https://doi.org/10.1016/j.matlet.2015.05.071

6. Chen, Y., Yuan, F., Guo, Y., Hu, D., Zhu, Z., Zhang, K., Zhu, S.: A novel mattress filling material comprising of luffa fibers and EVA resin. Ind. Crops Prod. 124, 213-221 (2018). https://doi. org/10.1016/j.indcrop.2018.07.074

7. Cecen, B., Kozaci, L.D., Yuksel, M., Ustun, O., Ergur, B.U., Havitciouglu, H.: Biocompatibility and biomechanical characteristics of loofah based scaffolds combined with hydroxyapatite, cellulose, poly-L-lactic acid with chondrocyte-like cells. Mater. Sci. Eng. C 91, 437-446 (2016). https://doi.org/10.1016/j.msec.2016.07.007

8. Ola, A.: Assessment of raw luffa as a natural hollow oleophilic fibrous sorbent for oil spill cleanup. Alexandria Eng. J. 53(1), 213-218 (2014). https://doi.org/10.1016/j.aej.2013.11.001

Open Access This chapter is licensed under the terms of the Creative Commons Attribution 4.0 International License (http://creativecommons.org/licenses/by/4.0/), which permits use, sharing, adaptation, distribution and reproduction in any medium or format, as long as you give appropriate credit to the original author(s) and the source, provide a link to the Creative Commons license and indicate if changes were made.

The images or other third party material in this chapter are included in the chapter's Creative Commons license, unless indicated otherwise in a credit line to the material. If material is not included in the chapter's Creative Commons license and your intended use is not permitted by statutory regulation or exceeds the permitted use, you will need to obtain permission directly from the copyright holder.

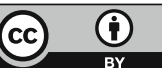

